\title{
Duration of the effect of fertility and insulin resistance on IVF or ICSI results in women with PCOS
}

\section{Mustafa Zakaria $^{1 *}$, Mohamed Zarqaoui ${ }^{2}$, Noureddine Louanjli ${ }^{3}$, Nisrine En-naciri ${ }^{4}$, Mohamed Ennaji ${ }^{5}$, Amal Kabit ${ }^{6}$, Naima El-yousfi ${ }^{7}$ and Romaissa Boutiche ${ }^{8}$}

${ }^{1}$ Northwestern University, Reproductive Biology, and Assisted Reproductive Technology, Consultant at IRIFIV Fertility Center, Administrative Deputy and Writer for the ART IRIFIV Scientific Research Group (AISRG) Casablanca, Morocco ${ }^{2}$ Strasbourg University Medicine Pole, Endoscopic Surgery Obstetrics and Gynecology FR, Coordinator of IRIFIV Fertility Center, Head of the ART IRIFIV Scientific Research Group (AISRG) Casablanca, Morocco ${ }^{3}$ Strasbourg University Medicine, Department of Clinical Biology, FR/Head of LABOMAC Laboratory of Clinical Analysis and Assisted Reproductive Technology IRIFIV Fertility Center, ANFA Fertility Center - Executive Vice President of the ART IRIFIV Scientific Research Group (AISRG) Casablanca, Morocco

${ }^{4}$ Ibn Zohr University Higher School of Technology Agadir, Biology, Senior Clinical Embryologist, Laboratory IVF Agadir, Souss-Massa, Member of the Scientific Research Group and Researcher in the Scientific Research Group, Agadir, Morocco ${ }^{5}$ University of Mohamed Naji Cadi Ayyad in Marrakech, Bachelor's Degree of Animal Biology, Senior Clinical Embryologist at IRIFIV Fertility Center, Member of the Scientific Research Group and Researcher in the Scientific Research Group, Casablanca, Morocco

${ }^{6}$ University Hassan II Aïn Chock, Faculty of Sciences and Techniques, Master's Degree Applied Biology (Pharmaceutical Quality Control), Senior Clinical Embryologist at IRIFIV Fertility Center, Member of the Scientific Research Group and Researcher in the Scientific Research Group, Casablanca, Morocco ${ }^{7}$ University Hassan II Aïn Chock, Faculty of Sciences and Techniques, Master's Degree of Biotechnology Applied to Plan Production and Food Industry, Senior Clinical Embryologist at Ibn Badis Fertility Center, Member of the Scientific Research Group and researcher in the Scientific Research Group, El Jadida, Morocco ${ }^{8}$ Universite des Sciences et de la Technologie Houari Boumediene, Mcs Molecular Pathology and Biotechnology, Clinical Embryologist, Laboratory IVF Algeria, Rotaby Fertility Center Algiera - Algiers, Member of the Scientific Research Group and researcher in the Scientific Research Group, Algeria

*Corresponding Author: Mustafa Zakaria, Consultant at IRIFIV Fertility Center, Administrative Deputy and Writer for the ART IRIFIV Scientific Research Group (AISRG), Casablanca, Morocco.
Received: October 03, 2020

Published: October 30, 2020

(C) All rights are reserved by Mustafa

Zakaria., et al. 


\section{Abstract}

The main effects of insulin resistance in the pathogenesis of PCOS, strategies to reduce insulin and improve reproductive parameters in PCOS patients and should be recommended for all overweight and obese patients, and the effects of insulin resistance on the results of IVF or sperm injection were examined. Intracytoplasmic (ICSI) in women with PCOS. Insulin sensitivity was measured by continuous glucose infusion with a form evaluation test (CIGMA). Insulin-resistant $(n=26)$ and non-insulin-resistant $(n=30)$ women with PCOS underwent a total of 100 cycles of long-term down-regulation with poserilin acetate, stimulation with recombinant human FSH, and IVF or ICSI. And the ovarian stimulation period for hormone tests. The insulin-resistant and non-insulin-resistant women had similar concentrations of FSH, LH, testosterone, and androstenedione during stimulation, but the insulin-resistant women had hyperinsulinemia and low concentrations of globulin associated with sex hormones. The insulin-resistant women also had low concentrations of estradiol during stimulation and required higher FSH doses, but these differences disappeared after controlling for higher body weight in the insulin-resistant group of women. Insulin resistance was neither associated with hormone levels nor with IVF outcomes. Obesity, regardless of insulin resistance, is associated with relative gonadal resistance, necessary to confirm these findings. In conclusion, it has been shown that reducing insulin resistance improves the ovulation rate in PCOS patients, but there is strong evidence to maintain the usefulness of insulin-causing drugs as a treatment option.

Keywords: Insulin Resistance and PCOS; Obesity and Insulin Resistance; Normal Insulin Sensitivity; Ovarian Stimulation and IVF; Stimulating Hormone and Tests; PCOS; Insulin Sensitivity Recombinant Follicle; Obesity is Associated with Limited Ovulation; AMH in Obese Patients

\section{Abbreviations}

PCOS: Symptoms of Polycystic Ovary Syndrome; IVF: In-vitro fertilization; ICSI: Intracytoplasmic Sperm Injection; HCG: Human Chorionic Gonadotrophin; WHO: World Health Organization; NIR: Noninsulin-Resistant; IR: Insulin-Resistant; CI: Confidence Interval; FSH: Follicle Stimulating Hormone; LH: Luteinizing Hormone; BMI: Body Mass Index; IR: Insulin Resistance; UEI: Unexplained Infertility; HOMA: Homeostatic Model Assessment; SHBG: Sex HormoneBinding Globulin; AMH: Anti-Mullerian Hormone

\section{Introduction}

Insulin resistance and PCOS

Symptoms of Polycystic Ovary Syndrome (PCOS), a major cause of infertility, are hyperandrogenism and chronic anovulation (Franks, 1995). Many women with PCOS show insulin resistance and hyperinsulinemia. Hyperinsulinemia in PCOS is attributed to obesity UI as well as to insulin resistance regardless of body weight (Dell., et al. 1992; Holty., et al. 1994; Deneve, 1997). Nonovulatory infertility in PCOS often responds to clomiphene citrate treatment, ovulation induction with gonadotrophin, or ovarian surgery. In cases where these attempts fail or other fertility problems coexist, IVF is the preferred treatment [1] (Dale., et al. 1991; Buyalos and Lee, 1996; Homburg, 1996). Obesity and insulin resistance however, with the most obvious effects, obesity and insulin resistance impair the success of fertility treatment in PCOS. In fact, obesity is more prevalent among non-ovulating women after ovarian electrocautery (Gjønnaess, 1994) and treatment with clomiphene citrate (Polson., et al. 1989; Imani., et al. 1998) [2,3]. Ovulation induction with gonadotrophins in obese women with PCOS requires higher doses than lean women with PCOS, the rate of ovulatory cycles is lower, the rate of multifollicular development and the incidence of miscarriage is higher in obesity (Hamilton-Fairley., et al. 1992; Friedstrom., et al. 1997). Obesity may also jeopardize IVF outcomes in PCOS: in fact, high intra-follicular concentrations of leptin - a hormone produced by adipose tissue - correlate with relative gonadal resistance during ovarian stimulation for IVF (Fedorcsák., et al.). Furthermore, robotic obesity - a common feature of PCOS - is associated with a lower pregnancy rate after IVF (Wass., et al. 1997) and obesity is also associated with an increased risk of miscarriage, partly due to a lower number of eggs retrieved in obese women [4-6] (Fedorcsák)., et al. 2000c). The independent effect of insulin resistance on infertility treatment in PCOS is less clear. Regardless of body weight, insulin-resistant women require higher doses of gonadotrophins during ovarian stimulation, and insulin resistance is also associated with a risk of multifollicular development and a high rate of abolition (Folgieso., et al. 1997; Dell., et al. 1998). Hyperinsulinemia PCOS women are more likely to produce eggs that show low fertility rates after IVF, and embryos that 
are unable to implant (Cano., et al. 1997). Moreover, the insulinresistant PCOS-derived luteinizing granulosa cells undergoing IVF release less progesterone in vitro than cells from non-insulin-resistant women (Fedorcsák., et al. 2000b) [7-10]. Exercise, following a low-calorie diet and insulin-lowering medications such as metformin, troglitazone, and acarbose reduce insulin levels, correct endocrine abnormalities caused by obesity and insulin resistance, and thus may improve infertility treatment outcomes (Pascuali., et al. 1997; Clark., et al. 1998; Nestler., et al. 1998; Ehrmann, 1999). If insulin resistance is weakening as a result of IVF in PCOS, this will require combined treatment with insulin-lowering drugs or weight reduction before and during lower regulation and ovarian stimulation. This led us to examine the effect of insulin resistance on the results of IVF or intracytoplasmic sperm injection (ICSI) in women with the syndrome (P Fedorcak., et al. 2001).

Normal insulin sensitivity

The age of insulin-resistant and non-insulin-resistant women was similar [median 30 years (range 23 - 38) versus 31 years (range 25 - 38); $\mathrm{P}=0.19$ ]. Insulin- resistant women had a higher body mass index (BMI) [median $28.9 \mathrm{~kg} / \mathrm{m}^{2}$ (range 18.8 - 36.3)] than non-insulin-resistant women [median $24.7 \mathrm{~kg} / \mathrm{m}^{2}$ (range 19.7-33.3); $\mathrm{P}=0.006]$; [11-13]. indeed, more insulin-resistant women were obese [18/26 (69\%) versus 13/30 (43\%); P = 0.05]. Baseline hormone concentrations reflected the effects of insulin resistance in PCOS: insulin-resistant women had higher fasting insulin and C-peptide concentrations, lower SHBG, but higher testosterone concentrations, and thus, higher free testosterone index; insulin-resistant women also had higher FSH concentrations and lower LH/FSH ratio (Figure 1). These differences in baseline hormone concentrations between insulin-resistant and non-insulinresistant groups remained similar after accounting for BMI by covariance analysis (data not shown) (P Fedorcak., et al. 2001).

\begin{tabular}{lcc}
\hline & $\begin{array}{l}\text { Non-insulin-resistant } \\
(n=30)\end{array}$ & $\begin{array}{l}\text { Insulin-resistant } \\
(n=26)\end{array}$ \\
\hline FSH (IU/I) & $4.6(2.7-7.0)$ & $5.65(3.0-8.6)^{\mathrm{a}}$ \\
LH (IU/1) & $13.0(2.3-32.4)$ & $12.1(5.1-18.7)$ \\
LH/FSH ratio & $2.7(0.6-7.0)$ & $2.0(0.9-5.2)$ \\
Testosterone (nmol/1) & $1.55(0.8-3.7)$ & $2.1(0.7-24.0)$ \\
Androstenedione (nmol/1) & $6.0(2.4-13.5)$ & $6.7(2.7-128.0)$ \\
SHBG (nmol/1) & $30.5(8.0-60.0)$ & $23.0(6.0-60.0)^{\mathrm{a}}$ \\
Free testosterone index (\%) & $5.2(2.1-27.3)$ & $11.4(3.0-50.0)^{\mathrm{b}}$ \\
Fasting insulin (pmol/1) & $102(59-196)$ & $150(71-491)^{c}$ \\
Fasting C-peptide (pmol/1) & $721(356-1504)$ & $1149(429-2120)^{\mathrm{b}}$ \\
\hline Values are median (range). & & \\
a $P<0.05 ;{ }^{b} P<0.01 ;{ }^{c} P<0.001$ by Mann-Whitney test. \\
SHBG = sex hormone-binding globulin.
\end{tabular}

Figure 1: Baseline hormone concentration in non-insulin-resistant and insulin-resistant women with polycystic ovarian syndrome (PCOS).

\section{Ovarian stimulation and IVF}

Pituitary function was suppressed with a daily dose of $600 \mathrm{mcg}$ buserelin acetate (Suprefact; Hoechst, Frankfurt, Germany). Lower regulation began 1 week prior to the expected occurrence of menstrual bleeding (or randomly in the case of menopause) and was usually administered for 4 weeks until no follicles of $>10 \mathrm{~mm}$ appeared on the vaginal ultrasound examination and serum oestradiol concentrations were $<0.2 \mathrm{nmol} / \mathrm{L}$. Follicular development then began with 75 or 150 IU of recombinant human FSH (Gonal F; Serono, Switzerland/Puregon; Organon, Netherlands) daily $[14,15]$. The daily dose was increased with 75 IU FSH every 3 - 4 days according to individual response. When the primary follicle was $>18$ $\mathrm{mm}$ and serum estradiol concentrations were 1 - $15 \mathrm{nmol} / \mathrm{L} \mathrm{de}-$ pending on follicle count, ovulation was stimulated with 10,000 IU of human chorionic gonadotropin (HCG) (Profasi; Serono). Buserelin acetate was administered until the day of the HCG injection. Cycles were canceled in the event of insufficient follicular growth (fewer than three follicles) or impending ovarian hyperstimulation (enlarged multifollicular ovaries $>10 \mathrm{~cm}$ in diameter and oestradiol concentrations $>10 \mathrm{nmol} / \mathrm{L}$ ). Follicles were aspirated within 34 - 38h after ovulation induction with HCG and the collected oocytes were fertilized in vitro by IVF or ICSI (Åbyholm., et al. 1991; Tanbo., et al. 1998) [1]. One or two embryos were transferred on the second, third, or fourth day after follicle puncture. Only three embryos could be transferred in selected cases. Progesterone (25 $\mathrm{mg} /$ day) was injected to support the luteal phase. Pregnancy was determined by plasma I-HCG concentration > $10 \mathrm{IU} / \mathrm{L}$ on day 14 after follicle puncture. Vaginal ultrasound examinations at 6 and 12 weeks of pregnancy confirmed the viability of the fetus or its abortion. The implantation rate was the ratio of the number of gestational sacs on a 6-week ultrasound scan to the total number of embryos transferred. Ovarian hyperstimulation syndrome was defined by ovarian hyperstimulation $>10 \mathrm{~cm}$ diameter, abdominal discomfort [consistent with WHO stages I and II], eventual ascites, and hydrocephalus or thrombotic abnormalities [16-19].

\section{Stimulating hormone and tests}

In the ratio assays for basic hormone assays, blood samples were collected during fasting, in the early follicular phase, from cycling women, or randomly in menopause. Blood samples were also taken on the day when FSH stimulation began, between days 4 and 6 of ovarian stimulation, and on the day of ovulation induction $[20,21]$. Serum concentrations of FSH, LH, oestradiol, Androstenedione, testosterone, sex hormone bound globulin (SHBG), glucose, insulin, and peptide $\mathrm{C}$ were determined using routine laboratory methods (Dale., et al. 1998). Briefly, FSH, LH, and oestradiol were measured using the dissociation-enhanced lanthanide fluoromonide assay (DELFIA; Wallac Oy, Turku, Finland); Testosterone, 
androstenedione, and SHBG were examined by radioimmunoassay (Dale., et al. 1998); Insulin and radioimmunoassay were measured with insulin mono-iodine and anti-insulin antagonist (Linko Research, St. Louis, Missouri, USA) (Dell., et al. 1998). Glucose concentrations were determined using the glucose oxidase method using the Elite ${ }^{\mathrm{TM}}$ glucometer (Bayer Diagnostics, Paris, France), while the C-peptide was tested with immunohistochemistry (Diagnostic Systems Laboratories, Webster, TX, USA). The free testosterone index was calculated using the formula: testosterone x 100/SHBG.

\begin{tabular}{|c|c|c|}
\hline & $\begin{array}{l}\text { Non-insulin resistant } \\
(n=30)\end{array}$ & $\begin{array}{l}\text { Insulin-resistant } \\
(n=26)\end{array}$ \\
\hline \multicolumn{3}{|c|}{ Ovarian stimulation, $I V F$ and embryo transfer } \\
\hline No. of started cycles & 61 & 39 \\
\hline No. of cycles per patient & $2(1-4)$ & $1(1-3)$ \\
\hline No. of ICSI cycles $(\%)$ & $7 / 61$ (11.5) & $3 / 39(7.7)$ \\
\hline $\begin{array}{l}\text { No. of days on GnRHa } \\
\text { before start of stimulation }\end{array}$ & $21.5(8-52)$ & $22(6-47)$ \\
\hline Total FSH dose (IU) & $1800(650-6750)$ & $2450(975-8005)^{2}$ \\
\hline No. of collected oocytes & $9(1-35)$ & $10(3-37)$ \\
\hline $\begin{array}{l}\text { No. of normal fertilized } \\
\text { oocytes }\end{array}$ & $5(0-20)$ & $5(1-23)$ \\
\hline $\begin{array}{l}\text { No. of cycles proceeding to } \\
\text { embryo transfer }(\%)\end{array}$ & $47 / 61(77)$ & $33 / 39(84.6)$ \\
\hline Day of embryo transfer & $3(2-4)$ & $3(2-4)$ \\
\hline No. of transferred embryos & $2(1-3)$ & $2(1-3)$ \\
\hline \multicolumn{3}{|l|}{ Cycle outcome } \\
\hline $\begin{array}{l}\text { Pregnancy rate per started } \\
\text { cycle }(\%)\end{array}$ & $22 / 61(36.1)$ & $14 / 38(36.8)$ \\
\hline $\begin{array}{l}\text { Pregnancy rate per embryo } \\
\text { transfer }\end{array}$ & $22 / 47(46.8)$ & $14 / 32(43.8)$ \\
\hline Implantation rate $(\%)$ & $25 / 89(28.1)$ & $17 / 65(26.2)$ \\
\hline Incidence of OHSS (ร) & $6 / 61(9.8)$ & $4 / 39(10.3)$ \\
\hline \multicolumn{3}{|l|}{ Pregnancy outcome } \\
\hline Delivery $(\%)$ & $18 / 22(82)$ & $9 / 14(64)$ \\
\hline Abortion before week 6 (\%) & $3(14)$ & $2(14)$ \\
\hline $\begin{array}{l}\text { Abortion between week } \\
6-12(\%)\end{array}$ & - & $3(21)$ \\
\hline Abortion after week $12(\%)$ & $1(4)$ & - \\
\hline
\end{tabular}

Data are median (range) or proportion (\%).

${ }^{a} P<0.05$ by Mann-Whitney test.

GnRHa $=$ gonadotrophin-releasing hormone agonist; ICSI =

intracytoplasmic sperm injection; OHSS = ovarian hyperstimulation syndrome.

Figure 2: Ovarian stimulation and IVF in PCOS women with or without insulin resistance.

\section{Statistical data comparison analysis}

Comparison of group data with Mann-Whitney test or 2 pedigree tests. Correlations between variables were assessed in a manner that takes into account the unequal number of treatment cycles in the patients. Thus, the Pearson correlation coefficient was calculated between the subject averages, while the means were weighted by the number of cycles; P-values were based on the number of patients and not on the total number of cycles (Bland and Altman, 1995) $[22,23]$. Cumulative pregnancy rates were calculated using the Kaplan-Meier method, and compared with the ranking test. Pvalue $<0.05$ was considered statistically significant (P Fedorcak., et al. 2001).

\begin{tabular}{|c|c|c|c|}
\hline & $\begin{array}{l}\text { Start of } \\
\text { stimulation }\end{array}$ & $\begin{array}{l}\text { Stimulation } \\
\text { days } 4-6\end{array}$ & $\begin{array}{l}\text { Day of HCG } \\
\text { administration }\end{array}$ \\
\hline \multicolumn{4}{|c|}{ FSH (IU/1) } \\
\hline NIR & $3.0(1.2-7.6)$ & $5.3(3.6-10.1)$ & $7.0(4.0-11.9)$ \\
\hline IR & $3.2(1.6-7.4)$ & $5.2(2.3-10.7)$ & $6.2(3.0-9.3)$ \\
\hline \multicolumn{4}{|c|}{ LH (IU/I) } \\
\hline NIR & $2.0(0.6-7.0)$ & $1.4(0.5-5.6)$ & $0.8(0.4-3.3)$ \\
\hline IR & $2.4(0.6-7.2)$ & $1.4(0.5-5.1)$ & $0.7(0.6-1.5)$ \\
\hline \multicolumn{4}{|c|}{ Oestradiol $(\mathrm{nmol} / /)$} \\
\hline NIR & $0.1(0.0-0.32)$ & $0.26(0.08-9.98)$ & $7.1(2.19-24.0)$ \\
\hline IR & $0.13(0.04-0.31)$ & $0.16(0.06-0.41)^{2}$ & $2.93(0.57-15.0)^{\mathrm{a}}$ \\
\hline \multicolumn{4}{|c|}{ Testosterone $(\mathrm{nmol} / \mathrm{)})$} \\
\hline NIR & $1.1(0.5-2.4)$ & $1.5(0.8-4.0)$ & $1.75(1.2-3.6)$ \\
\hline IR & $1.4(0.5-2.9)$ & $1.1(0.5-6.7)$ & $2.1(0.5-3.5)$ \\
\hline \multicolumn{4}{|c|}{ Androstenedione (nmol/1) } \\
\hline NIR & $2.7(1.7-7.0)$ & $3.85(1.7-10.9)$ & $7.2(2.6-117.0)$ \\
\hline IR & $3.6(1.2-8.1)$ & $3.1(1.8-7.7)$ & $6.7(5.1-13.6)$ \\
\hline \multicolumn{4}{|c|}{ SHBG $(\mathrm{nmol} / 1)$} \\
\hline NIR & $33.5(12-84)$ & $39(12-82)$ & $59(21-152)$ \\
\hline IR & $26(6-87)$ & $25.5(7-76)^{2}$ & $46.5(24-153)$ \\
\hline \multicolumn{4}{|c|}{ Fasting insulin $(\mathrm{pmol} / \mathrm{l})$} \\
\hline NIR & $122.5(62-296)$ & $124.5(67-220)$ & $134.5(74-609)$ \\
\hline IR & $185.5(152-495)^{\mathrm{a}}$ & $245.5(102-1312)$ & $163(100-827)$ \\
\hline
\end{tabular}

Figure 3: Hormone concentrations in non-insulin-resistant (NIR) and insulin-resistant (IR) Women with PCOS on the day when FSH stimulation was started, between days 4 and 6 of Ovarian stimulation, and on the day of ovulation induction.

\section{Discussion}

insulin sensitivity recombinant follicle

Besides stimulating androgen synthesis, insulin was also shown to increase aromatase activity in isolated granulosa cells in vitro (Poretsky., et al. 1988; Erickson., et al. 1990; Pierro., et al. 1997) [24-26]. Nonetheless, in the current study similar oestradiol concentrations were found in insulin-resistant and non-insulin-resistant women after controlling for differences in body weight, and the number of collected oocytes was also alike-suggesting that estradiol synthesis per growing ovarian follicle was similar between groups. These findings do not support the fact that stimulation 
of aromatase by insulin in vitro results in an increased oestradiol release in hyperinsulinaemic PCOS women in vivo. Several causes may account for this disparity: the intricate mechanism that regulates aromatase activity in vivo, including gonadotrophins, GnRH, androgens and growth factors [27]. (Richards, 1994), may have a more pronounced effect on ovarian steroid secretion than does insulin, particularly when women receive long-term GnRH agonist treatment. Furthermore, long-standing hyperinsulinaemia may down-regulate insulin receptors in the ovary, and as a result reduce insulin's effect on granulosa cells (Samoto., et al. 1993; Fedorcsák., et al. 2000b). Insulin resistance in PCOS is also associated with an impaired progesterone synthesis by cultured granulosa-lutein cells in vitro (Fedorcsák., et al. 2000b) [28]. Such a defect of progesterone release during the luteal phase may impair outcome of lowdose FSH stimulation in insulin-resistant PCOS women (Fulghesu., et al. 1997; Dale., et al. 1998), since luteal phase support is usually not given with ovulation induction protocols. During long-term down-regulation and ovarian stimulation for IVF or ICSI, women receive luteal support (in the current study, progesterone), which may hence overcome impaired corpus luteal function in hyperinsulinaemia. Taken together, the results of the present study show that the effects that hyperinsulinaemia has on ovarian steroid synthesis in vitro or during low-dose FSH stimulation in vivo are minor when PCOS women receive long-term down-regulation and stimulation with recombinant FSH. In contrast to insulin resistance, obesity had a marked impact on infertility treatment in PCOS women. Indeed, it was also found that obesity is associated with higher gonadotrophin requirement during stimulation, and fewer collected oocytes. These effects were independent of the insulin resistance index, suggesting that factors other than hyperinsulinaemia contribute to relative ovarian gonadotrophin resistance in obesity. One such factor could be the altered pharmacokinetics of gonadotrophins in obese women, resulting in lower effective concentrations of exogenous FSH (Fridström., et al. 1997) [29]. Another possible factor inducing gonadotrophin resistance is the adipocyte-derived hormone, leptin. Indeed, leptin inhibits the stimulatory effect of FSH on steroid synthesis by granulosa cells in vitro (Zachow and Magoffin, 1997; Agarwal., et al. 1999), and high intrafollicular leptin concentrations are associated with relative gonadotrophin resistance in obese PCOS women (Fedorcsák., et al. 2000a) [30]. In either way, increased gonadotrophin doses to compensate for relative gonadotrophin resistance induced by obesity might result in impaired oocyte or embryo quality, implantation failure and pregnancy complications. Indeed, superovulation in mice induces various defects, such as abnormal embryonic development and decreased invasional capacity of blastocysts in vitro, lower implanta- tion rate, delayed implantation, increased length of gestation, lower birth weight and developmental retardation in vivo (Ertzeid and Storeng, 1992; Ertzeid., et al. 1993). Although these defects were shown in mice, in the current study no significant differences were found in conception rate and pregnancy outcome between insulinresistant and non-insulin-resistant women, even though hyperinsulinaemic women received higher FSH doses.

\section{Obesity is associated with limited ovulation}

Obesity is associated with limited ovulation, leading to limited fertilization and menstrual disturbance. This also causes insufficient implantation [31]. Some studies report that overweight and obese sub fertile women have reduced fertility treatment success, and their pregnancies are related to more complication [32,33]. Other studies have reported that weight loss helps to improve ovulation progress and infertility treatment outcomes. One study showed that less follicular development occurred in obese women and higher dose medication in treatment was required. Moreover, IR is further increased in case of obesity. Short term weight loss (4 - 6 months) reduces IR, serum insulin, abdominal fat accumulation, and androgens, and would contribute positively to the lipid profile. We observed that the two groups were similar in terms of BMI. We also sought to clarify whether IR is independent of BMI in UEI cases. There are many reports in the literature that BMI positively correlates with HOMA-IR [34,35]. Likewise, we found a significant positive correlation between BMI and HOMA-IR in women with UEI. Studies on infertility and IR are mostly related to PCOS patients [36]. It is claimed that IR plays an important role in the pathogenesis of PCOS and may be obesity independent, although more pronounced in obesity [37].

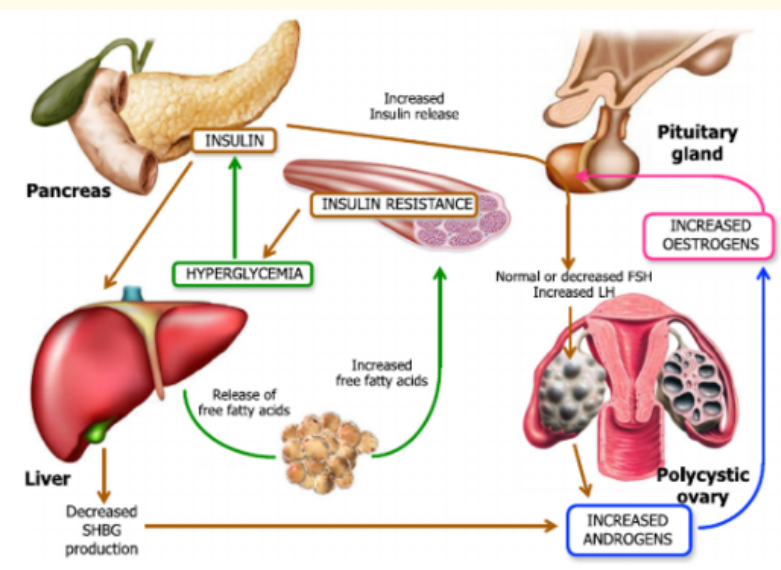

Figure 4: Pathophysioly of insuline resistance. 
This figure illustrates the complex interactions underlying the pathophysiology of PCOS. Insulin resistance and the resulting hyperinsulinemia are responsible for the majority of the changes found in PCOS. Insulin resistance in PCOS does not occur in all tissues, but rather appears to be tissue-specific. Skeletal-muscle and adipose tissue become insulin resistance resulting in decrease glucose uptake and increased lipolysis, respectively, whereas the ovary, adrenal and liver remain insulin sensitive. In PCOS, hyperinsulinemia occurs as a compensatory response to insulin resistance. This resulting hyperinsulinemia has a stimulatory effect on the ovaries and adrenal glands that leads to enhanced androgen production by these organs. More specifically, excess insulin enhances androgen production in ovarian theca cells in response to luteinizing hormone (LH) stimulation, resulting in follicular arrest and anovulation. In contrast hyperinsulinemia acts to suppress hepatic production of sex hormone-binding globulin (SHBG), the primary binding protein for testosterone in the serum. Therefore, insulin resistance with compensatory hyperinsulinemia results in hyperandrogenemia (Silvestris., et al. 2018).

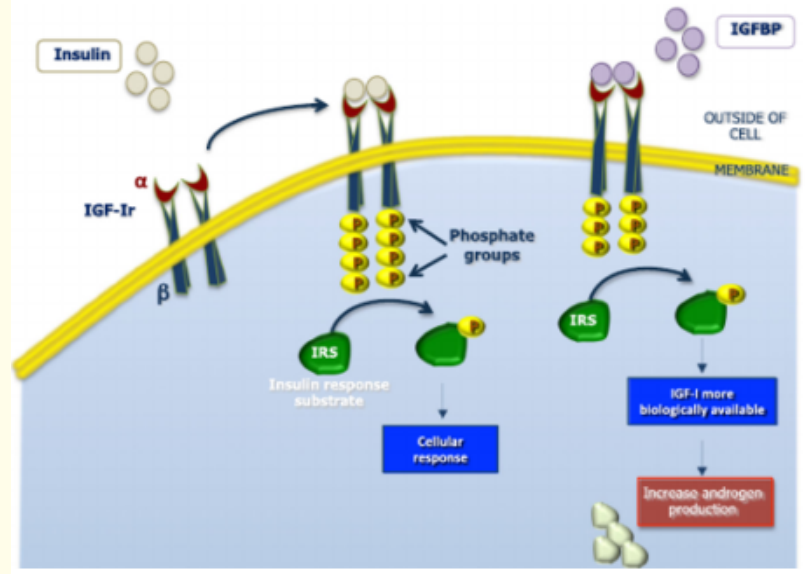

Figure 5: Insulin receptor tyrosine kinases. The $\alpha$ subunit binds insulin and the $\beta$ transmits a signal from bound insulin to the cytoplasm.

The insulin signal activates the receptor's protein kinases domain in the cytoplasm. Protein kinases from the receptor phosphorylate insulin-response substrates triggering other chemical responses inside the cell. When IGFBPs binds and therefore activates the IGF-Ir, the hepatic synthesis of IGFBP-I is decreased, making IGF-I more biologically available, thus enhancing androgen production by theca interstitial and stromal cells.

\section{AMH in obese patients}

Anti-Mullerian hormone (AMH) is a product of the granulosa cells of small antral and pre-antral follicles, and clinically, it may be reflective of the prediction of ovarian reserve in women undergoing fertility evaluation and treatment [38] (Silvestris., et al. 2018). For this reason, is important to evaluate the change in the levels of $\mathrm{AMH}$, as a fertility parameters in obese women with or without PCOS, sub-mitted to aerobic exercise with the aim of losing weight. The slimming via exercise or diet is considered one of the most important targets in lifestyle modification pro-grammes capable to induce an improvement in repro-ductive function among obese women with PCOS [39] (Silvestris., et al. 2018). Exercise interventions of moderate activity are one of the most important lifestyle modifications that positively influence on fertility and assisted reproductive technology outcomes [40] (Silvestris., et al. 2018).

\section{Conclusion}

In conclusion, serum hormone concentrations of insulin-resistant and non-insulin-resistant PCOS women were similar after controlling for body weight, and insulin resistance did not affect the outcome of IVF treatment in this study. Obesity, however, independently of insulin resistance, was associated with a relative gonadotrophin resistance, as shown by higher gonadotrophin requirement, a lower number of collected oocytes and lower peak oestradiol concentrations (P Fedorcak., et al. 2001). Overweight and obese women need longer time to conceive and undoubtedly are at higher risk of infertility. Higher BMI is also associated with adverse pregnancy outcomes, such as gestational diabetes and hypertension and women undergoing under going in vitro fertilization may experience negative outcomes at higher rate than normal weight females. However, as early symptoms of dysfunctional oocyte maturation and hormone derangements, oligomenorrhea and alterations of menstrual cycles should primarily alert overweight and obese women on their potentially defective fertility. The impact of obesity on reproductive function, especially associated with ovulatory disorders, is mainly due to neuroendocrine mechanisms, which interfere with ovarian functions, and are able to affect the ovulation rate and the endometrial receptivity (Silvestris., et al. 2018).

\section{Bibliography}

1. Dale PO., et al. "Body weight, hyperinsulinemia, and gonadotropin levels in the polycystic ovarian syndrome: evidence of two distinct populations". Fertility and Sterility 58 (1992): 487-491. 
2. Adams J., et al. "Multifollicular ovaries: clinical and endocrine features and response to pulsatile gonadotropin releasing hormone". Lancet 2 (1985): 1375-1379.

3. Clark AM., et al. "Weight loss in obese infertile women results in improvement in reproductive outcome for all forms of fertility treatment". Human Reproduction 13 (1998): 1502-1505.

4. Bland JM and Altman DG. "Calculating correlation coefficients with repeated observations: Part 2. Correlation between subjects". British Medical Journal 310 (1995): 633.

5. Buyalos RP and Lee CT. "Polycystic ovary syndrome: pathophysiology and outcome with in vitro fertilization". Fertility and Sterility 65 (1996): 1-10.

6. Cano F., et al. "Oocyte quality in polycystic ovaries revisited: identification of a particular subgroup of women". Journal of Assisted Reproduction and Genetics 14 (1997): 254-261.

7. Agarwal SK., et al. "Leptin antagonizes the insulin-like growth factor-I augmentation of steroidogenesis in granulosa and theca cells of the human ovary". The Journal of Clinical Endocrinology and Metabolism 84 (1996): 1072-1076.

8. Dale PO., et al. "In-vitro fertilization in infertile women with the polycystic ovarian syndrome". Human Reproduction 6 (1991): 238-241.

9. Åbyholm T., et al. "The first attempt at IVF treatment. Results and requirements for a satisfactory success rate". European Journal of Obstetrics and Gynecology and Reproductive Biology 38 (1991): 125-132.

10. Dale PO., et al. "The impact of insulin resistance on the outcome of ovulation induction with low-dose follicle stimulating hormone in women with polycystic ovary syndrome". Human Reproduction 13 (1998): 567-570.

11. Dunaif A. "Insulin resistance and the polycystic ovary syndrome: mechanism and implications for pathogenesis". Endocrine Reviews 18 (1997): 774-800.

12. Ehrmann DA. "Insulin-lowering therapeutic modalities for polycystic ovary syndrome". Endocrinology and Metabolism Clinics of North America 28 (1999): 423-438.

13. Erickson GF., et al. "The effects of insulin and insulin-like growth factors-I and -II on estradiol production by granulosa cells of polycystic ovaries". The Journal of Clinical Endocrinology and Metabolism 70 (1990): 894-902.

14. Ertzeid G and Storeng R. "Adverse effects of gonadotrophin treatment on pre-and postimplantation development in mice". Reproduction, Fertility and Development 96 (1992): 649-655.
15. Ertzeid G., et al. "Treatment with gonadotropins impaired implantation and fetal development in mice". Journal of Assisted Reproduction and Genetics 10 (1993): 286-291.

16. Fedorcsák P., et al. "Leptin and leptin binding activity in the preovulatory follicle of polycystic ovary syndrome patients". Scandinavian Journal of Clinical and Laboratory Investigation 60 (2000): 649-655.

17. Fedorcsák P., et al. "Impaired insulin action on granulosa-lutein cells in women with polycystic ovary syndrome and insulin resistance". Gynecology Endocrinology 14 (2000): 327-336.

18. Fedorcsák P., et al. "Obesity is associated with early pregnancy loss after IVF or ICSI". Acta Obstetricia et Gynecologica Scandinavica 79 (2000): 43-48.

19. Franks S. "Polycystic ovary syndrome". The New England Journal of Medicine 333 (1995): 853-861.

20. Franks S., et al. "Insulin action in the normal and polycystic ovary". Endocrinology and Metabolism Clinics of North America 28 (1999): 361-378.

21. Fridström M., et al. "Serum FSH levels in women with polycystic ovary syndrome during ovulation induction using downregulation and urofollitropin". European Journal of Endocrinology 136 (1997): 488-492.

22. Fulghesu AM., et al. "The impact of insulin secretion on the ovarian response to exogenous gonadotropins in polycystic ovary syndrome". The Journal of Clinical Endocrinology and Metabolism 82 (1997): 644-648.

23. Gjønnaess H. "Ovarian electrocautery in the treatment of women with polycystic ovary syndrome (PCOS). Factors affecting the results". Acta Obstetricia et Gynecologica Scandinavica 73 (1994): 407-412.

24. Hamilton-Fairley D., et al. "Association of moderate obesity with a poor pregnancy outcome in women with polycystic ovary syndrome treated with low dose gonadotrophin". British Journal of Obstetrics and Gynaecology 99 (1992): 128-131.

25. Holte J., et al. "Enhanced early insulin response to glucose in relation to insulin resistance in women with polycystic ovary syndrome and normal glucose tolerance". The Journal of Clinical Endocrinology and Metabolism 78 (1994): 1052-1058.

26. Homburg R. "Polycystic ovary syndrome-from gynaecological curiosity to multisystem endocrinopathy". Human Reproduction 11 (1996): 29-39.

27. Hosker JP., et al. "Continuous infusion of glucose with model assessment: measurements of insulin resistance and beta-cell function in man". Diabetologia 28 (1985): 401-411. 
28. Imani B., et al. "Predictors of patients remaining anovulatory during clomiphene citrate induction of ovulation in normogonadotropic oligoamenorrheic infertility". The Journal of Clinical Endocrinology and Metabolism 83 (1995): 2361-2365.

29. Nestler JE., et al. "Effects of metformin on spontaneous and clomiphene-induced ovulation in the polycystic ovary syndrome". The New England Journal of Medicine 338 (1998): 1876-1880.

30. Pasquali R., et al. "Weight control and its beneficial effect on fertility in women with obesity and polycystic ovary syndrome". Human Reproduction 12 (1997): 82-87.

31. Pierro E., et al. "Further evidence of increased aromatase activity in granulosa luteal cells from polycystic ovary". Human Reproduction 12 (1997): 1890-1896.

32. Polson DW., et al. "Induction of ovulation with clomiphene citrate in women with polycystic ovary syndrome: the difference between responders and nonresponders". Fertility and Sterility 51 (1989): 30-34.

33. Poretsky L., et al. "The effects of experimental hyperinsulinemia on steroid secretion, ovarian [125I]insulin binding, and ovarian [125I] insulin-like growth-factor I binding in the rat". Endocrinology 122 (1988): 581-585.

34. Richards JS. "Hormonal control of gene expression in the ovary". Endocrine Reviews 15 (1994): 725-751.

35. Samoto T., et al. "Altered expression of insulin and insulin-like growth factor-I receptors in follicular and stromal compartments of polycystic ovaries". Endocrine Journal 40 (1993): 413-424.

36. Tanbo T., et al. "Intracytoplasmic sperm injection". Tidsskrift for den Norske laegeforening 118 (1998): 864-869.

37. Wass P., et al. "An android body fat distribution in females impairs the pregnancy rate of in-vitro fertilization-embryo transfer". Human Reproduction 12 (1997): 2057-2060.

38. Zachow RJ and Magoffin DA. "Direct intraovarian effects of leptin: impairment of the synergistic action of insulin-like growth factor-I on follicle- stimulating hormone-dependent estradiol-17 beta production by rat ovarian granulosa cells". Endocrinology 138 (1997): 847-850.

39. Yogev Y and Catalano PM. "Pregnancy and obesity". Obstetrics and Gynecology Clinics of North America 36.2 (2009):285-300.

40. Al-Nuaim LA. 'The impact of obesity on reproduction in women". Saudi Medical Journal 32.10 (2011):993-1002.

\section{Assets from publication with us}

- Prompt Acknowledgement after receiving the article

- Thorough Double blinded peer review

- Rapid Publication

- Issue of Publication Certificate

- High visibility of your Published work

Website: www.actascientific.com/

Submit Article: www.actascientific.com/submission.php Email us: editor@actascientific.com

Contact us: +919182824667 